\title{
La construcción de un sistema de integridad institucional en la Administración de Castilla y León (2007-2021)1
}

\author{
The construction of a system of institutional integrity in the \\ Administration of Castilla y León (2007-2021)
}

\author{
Luis Heredero Ortiz de la Tabla \\ Cuerpo Superior de la Administración de Castilla y León (España) \\ ORCID: https://orcid.org/0000-0003-4982-5532 \\ luisheredero68@gmail.com
}

\begin{abstract}
NOTA BIOGRÁFICA
Doctor en Derecho y Máster en Ciencia Política por la Universidad de Salamanca y Funcionario del Cuerpo Superior de la Administración de Castilla y León. El autor combina su experiencia de gestión con la tarea investigadora, una de cuyas líneas la constituye la Administración en la que sirve como funcionario, la de Castilla y León, y que formó parte del objeto de su investigación doctoral en Derecho Administrativo. Su formación se completa con un máster de Ciencia Política, disciplina le ha permitido ofrecer un nuevo enfoque a su línea de investigación.
\end{abstract}

\begin{abstract}
RESUMEN ${ }^{2}$
La extendida percepción de corrupción y la correlativa desafección de los ciudadanos hacia la política y las instituciones han dado lugar a la puesta en marcha de políticas públicas destinadas a atajar y prevenir esas prácticas inadecuadas. La Administración de Castilla y León no es una excepción en este panorama, y ante la inexistencia de observatorios o estudios de opinión que evalúen su situación, resulta oportuno efectuar un análisis acerca de la política de integridad institucional desarrollada por la Junta de Castilla y León. Este trabajo trata de dar respuesta a la siguiente pregunta: ¿los instrumentos de regeneración democrática que ha adoptado la Administración de Castilla y León entre los años 2007 y 2021 conforman un verdadero «sistema de integridad institucional»? Como resultado principal de esta investigación se concluye que en Castilla y León se han implementado numerosas medidas de regeneración democrática que pueden conformar un sistema de integridad institucional, pero se encuentran aún en proceso de formación y desarrollo, y falta un sistema continuo de evaluación que le proporcione la denominación de «integral».
\end{abstract}

\section{PALABRAS CLAVE}

Castilla y León; integridad; corrupción; evaluación; administración.

\section{ABSTRACT}

The widespread perception of corruption and the correlative disaffection of citizens towards politics and institutions have generated the implementation of public policies aimed at tackling and preventing these

1 Este trabajo ha sido posible gracias a la inestimable contribución, supervisión y apoyo de la profesora titular de Ciencia Política de la Universidad de Salamanca, Araceli Mateos Díaz.

2 El autor agradece a los dos evaluadores anónimos y a los editores su tarea de revisión y sus propuestas de mejora, que han permitido mejorar la versión final del artículo. 
inappropriate practices. The Administration of Castilla y León is no exception in this panorama, and in the absence of observatories or opinion studies that evaluate its situation, it is acuratte to carry out an analysis of the institutional integrity policy developed by the Junta de Castilla y León. This paper tries to answer the following question: do the instruments of democratic regeneration that the Administration of Castilla y León has adopted between 2007 and 2021 make up a true "system of institutional integrity»? As a main result of this research, it is concluded that in Castilla y León numerous measures of democratic regeneration have been implemented that can form a system of institutional integrity, but they are still in the process of formation and development, and there is a lack of a continuous evaluation system that provides the denomination of «integral».

\section{KEYWORDS}

Castilla y León; integrity; corruption; evaluation; administration.

\section{SUMARIO}

INTRODUCCIÓN. 1. FUNDAMENTOS HISTÓRICOS, TEÓRICOS Y COMPARADOS DE LA POLÍTICA DE INTEGRIDAD PÚBLICA. PRIMER ACERCAMIENTO AL CASO DE CASTILLA Y LEÓN. 1.1. LA INTEGRIDAD EN EL SECTOR PÚBLICO: UNA PREOCUPACIÓN RECIENTE. 1.2. CONTEXTO EN EL QUE SE IMPLEMENTAN MEDIDAS FAVORABLES A LA INTEGRIDAD EN CASTILLA Y LEÓN. 1.2.1. La percepción de los ciudadanos en torno a la corrupción y sus factores potenciadores. 1.2.2. La configuración de la Administración de Castilla y León y de su sistema normativo. 1.3. LAAPARICIÓN DE UNA POLÍTICA PÚBLICA DE INTEGRIDAD. 1.3.1. Concepto de integridad pública. 1.3.2. El abordaje de la integridad desde la gobernabilidad y la gobernanza. 1.3.3. El abordaje de la integridad pública desde su evaluación. 1.3.4. Operacionalización del concepto de «sistema institucional de integridad». 2. APROXIMACIÓN METODOLÓGICA. 2.1. PREGUNTAS E HIPÓTESIS DE INVESTIGACIÓN. 2.2. UNIDAD DE ANÁLISIS Y REFERENTE TEMPORAL. 3. LA IMPLEMENTACIÓN DE MEDIDAS DE INTEGRIDAD PÚBLICA EN LA ADMINISTRACIÓN DE CASTILLA Y LEÓN. 3.1. PRIMERA DIMENSIÓN: REFORZAMIENTO INSTITUCIONAL. 3.1.1. Subdimensión Gobernanza. 3.1.2. Subdimensión prevención. 3.2. SEGUNDA DIMENSIÓN: CULTURA DE LA INTEGRIDAD. 3.2.1. Subdimensión códigos de conducta. 3.2.2. Subdimensión difusión. 3.3. TERCERA DIMENSIÓN: RENDICIÓN DE CUENTAS. 3.3.1. Subdimensión Canales de quejas y denuncias. 3.3.2. Subdimensión Sistemas de Evaluación. 3.3.3. Subdimensión órganos de garantía. CONCLUSIONES. REFERENCIAS BIBLIOGRÁFICAS.

\section{INTRODUCCIÓN}

Este artículo trata de cubrir un vacío en torno al análisis de la integridad pública referido al ámbito de la Administración de Castilla y León. En concreto, se trata de averiguar si la Junta de Castilla y León cuenta con una política pública que se pueda denominar como sistema de integridad institucional, o si por el contrario, las medidas adoptadas hasta el momento son el resultado de propulsiones administrativas o políticas esporádicas.

Tomamos como referencias para nuestro propósito la Recomendación sobre Integridad Pública que publicó la OCDE en 2017, junto con las aportaciones de Jiménez (2020), y de otros autores Villoria, 2018; Campos, 2020a; Campos, 2020b; González, 2006; Palomar, 2016), ya que ofrecen un modelo que mantiene una concepción holística de la integridad institucional. Se relega la alternativa de Transparencia Internacional en su trabajo sobre el Sistema Nacional de Integridad (2012), porque cuenta con una perspectiva inabarcable en un trabajo de esta naturaleza, en la medida en la que incorpora en su ámbito subjetivo al poder legislativo, al judicial, la sociedad civil, los negocios o los partidos políticos, entre otros.

Con esos referentes llevamos a cabo una operacionalización del concepto de sistema de integridad pública en dimensiones, subdimensiones e indicadores. Esto va a facilitar una medición y evaluación de los instrumentos, procesos y órganos implementados por la Administración de Castilla y León y valorar si conforman un verdadero sistema de integridad institucional. Todo ello en un período suficientemente amplio (2007-2021), que abarca varias legislaturas, con gobiernos del mismo partido pero con diferentes apoyos parlamentarios.

El trabajo concluye aseverando la existencia de un sistema de integridad institucional en Castilla y León que se encuentra en proceso de formación, en algunos aspectos bastante consolidado, pero que todavía adolece un sistema permanente de evaluación. 
GAPP. Nueva Época - N. 28, marzo 2022 - ISSN: 1989-8991 - DOI: https://doi.org/10.24965/gapp.i28.10971 - [Págs. 27-47]

La estructura de este documento se encuentra dividida en cuatro partes: la primera, describe el marco teórico, histórico y comparado de la política de integridad pública; en la segunda se presenta la metodología utilizada; la tercera es la parte nuclear del trabajo, y está dedicada a la identificación de los mecanismos de integridad pública que se han puesto en marcha; y por último, las conclusiones de la investigación.

\section{FUNDAMENTOS HISTÓRICOS, TEÓRICOS Y COMPARADOS DE LA POLÍTICA DE INTEGRIDAD PÚBLICA. PRIMER ACERCAMIENTO AL CASO DE CASTILLA Y LEÓN}

\subsection{La integridad en el sector público: una preocupación reciente}

Hasta el último cuarto del siglo xx no comenzó una verdadera preocupación por la integridad en la Administración Pública. Desde entonces se han multiplicado las normas de muy distinto rango, las recomendaciones, la literatura, los códigos deontológicos, los congresos, conferencias, foros y reuniones que abordan la cuestión (González, 2006, p. 28).

En el ámbito internacional, aparecerían la «Convención Interamericana contra la Corrupción» (1996), la «Convención de la OCDE para combatir el Cohecho de funcionarios Públicos Extranjeros en Transacciones Comerciales Internacionales» (1997), el «Libro Blanco sobre Gobernanza en la Unión Europea» (2001), y la «Convención de Naciones Unidas contra la Corrupción» (2003). La preocupación por la integridad en el ámbito internacional cobra su máxima relevancia con los «Objetivos de Desarrollo Sostenible» (2015), entre los que se encuentra el objetivo 16 «paz, justicia e instituciones sólidas», que incorpora las metas: corrupción y sobornos, instituciones eficaces y transparentes, y participación ciudadana.

Paralelamente había comenzado la proliferación de los códigos de conducta nacionales, como el de Nueva Zelanda (1990), Portugal (1991), Estados Unidos (1992), Reino Unido (1995) o Canadá (1996) (Diego Bautista, 2005, pp. 127-128). Al tiempo que se producía la eclosión del derecho de acceso a la información pública tuvo lugar en la primera década de este siglo XXI (Fernández, 2018, p. 221).

En España hubo que esperar a 2005 para la aprobación del «Código de Buen Gobierno de los miembros del Gobierno y de los altos cargos de la Administración General del Estado». En 2013 llegaría la Ley de transparencia, acceso a la información pública y buen gobierno, y en el ámbito normativo sectorial, encontramos regulación muy reciente sobre la integridad, transparencia y conducta en legislación sobre procedimiento y régimen jurídico de la Administración (2015), empleados públicos (2015) y sobre contratación administrativa (2017). Esta tendencia a la producción normativa tuvo su correlato en las Comunidades Autónomas a partir de comienzos de la segunda década del siglo XXI.

\subsection{Contexto en el que se implementan medidas favorables a la integridad en Castilla y León}

A continuación se analizan algunas particularidades existentes en el contexto político y social que permiten entender y explicar las posibilidades y limitaciones de las medidas favorables a la integridad en Castilla y León.

\subsubsection{La percepción de los ciudadanos en torno a la corrupción y sus factores potenciadores}

Si bien la corrupción no suponía novedad alguna en España, con el cambio de siglo empezaron a destaparse casos especialmente relevantes que afectaron a partidos políticos, a gobiernos, e incluso a la Casa Real. Esto provoca que, según datos del CIS, se pasara de un 1,9\% de los españoles que percibían la corrupción y el fraude como el principal problema en 2007, a un 55,5\% en 2015. Según Villoria (2015b, p. 19) con datos del Eurobarómetro de 2013 , un $95 \%$ de los españoles creían que había corrupción en las instituciones nacionales del país. El Eurobarómetro y el CIS de 2020 confirman esta tendencia.

A pesar de que el repositorio de datos sobre procesos de corrupción del Consejo General del Poder Judicial no ofrece datos alarmantes sobre corrupción en juzgados y tribunales de Castilla y León, y que no contamos con datos de opinión específicos para esta comunidad, no hay nada que haga pensar que la situación pudiera ser diferente.

Cinco factores podrían estar condicionando dicha percepción en esta comunidad:

1. La lucha política. En Castilla y León el uso de la corrupción en sede parlamentaria es frecuente mediante, por ejemplo, la solicitud de creación de una Oficina de Lucha Contra la Corrupción (PNL 8-02-2018), la información sobre tramas nacionales de corrupción y su incidencia en la comunidad (preguntas orales al 
GAPP. Nueva Época - N. 28, marzo 2022 - ISSN: 1989-8991 - DOI: https://doi.org/10.24965/gapp.i28.10971 - [Págs. 27-47]

La construcción de un sistema de integridad institucional en la Administración de Castilla y León (2007-2021)

presidente 12/6/2018 Gürtel, y 11-9-2018 Enredadera), la propuesta de comisiones de investigación (tres en funcionamiento en la actualidad), e incluso la interposición de una moción de censura (marzo 2021).

2. Los medios de comunicación. El sistema comunicativo de Castilla y León responde a las características de uno de los tres modelos mediáticos de Hallin y Mancini (2008, p. 167): el modelo pluralista polarizado. En esta Comunidad puede valorarse como alto «el grado de vinculación o el paralelismo político que hay entre los mass media, los partidos políticos y otras instituciones de la sociedad civil», y también «la presencia y las formas de intervención estatal en el campo de la comunicación mediática». De hecho, el Estatuto de Autonomía habilita a las instituciones para que intervengan en la configuración de los medios de comunicación. Además, aunque Castilla y León no tiene un ente público de radio y televisión, la televisión regional existente, gestionada por una sociedad de capital $100 \%$ privado, cuenta con un importante apoyo económico: durante 2014-2018, la Junta de Castilla y León concedió una subvención de 18 millones de euros anuales.

3. La lentitud de la justicia. En el largo período que discurre desde el momento en el que se abre investigación hasta el momento en el que se archiva el procedimiento o se sobresee, se traslada a la opinión pública una sensación que afecta muy negativamente a la percepción sobre la integridad pública. No es infrecuente que el político dimisionario por un asunto de corrupción se encuentre, años después de su dimisión, con el archivo de su causa. Ese puede ser el motivo por el que la Fiscalía Superior de Castilla y León reclamó en la Memoria Fiscal 2020 la creación de la figura del delegado de la Fiscalía Especial contra la Corrupción y el Crimen Organizado, y de unidades de funcionarios especializados en la investigación de estos delitos.

4. La crisis económica de 2007, y las consecuencias que ésta produjo pusieron en el punto de mira la actividad de los políticos. Las mismas conductas corruptas que en momentos de bonanza económica pasan desapercibidas para los ciudadanos, en situación económica desfavorable son fuertemente castigadas electoralmente (Muñoz, 2013; Villoria y Jiménez, 2012, p. 123).

5. El surgimiento de una reforzada interacción de la Administración con la sociedad, ya que los ciudadanos exigen más información, más participación y más responsabilidad en los asuntos públicos (Lizárraga, 2011, p. 127). Ello conlleva unas nuevas formas de relación de los ciudadanos con la Administración en un mundo global y en red (O'Toole, 1997).

\subsubsection{La configuración de la Administración de Castilla y León y de su sistema normativo}

La Administración de Castilla y León presenta como peculiaridad un origen y una dimensión marcada por la austeridad, unas estructuras no sobredimensionadas en comparación con otras administraciones similares, y un diseño articulado para prestar servicios en un territorio de 94.225 kilómetros cuadrados que cuenta con nueve provincias y 2.248 municipios (Heredero, 2009, pp. 225-231, 367).

Sin embargo, la disciplina organizativa de la administración castellanoleonesa no tiene correspondencia con el sistema normativo que da soporte a su actividad. El informe de la CEOE titulado «La producción normativa en 2019» afirma que España posee un "entramado normativo complejo, inherente a un sistema de gobernanza multinivel», que provoca que en el territorio español se apliquen normas internacionales, europeas, estatales, autonómicas y locales. En el ámbito estatal en el año 2019 se aprobaron 648 normas, lo que supone un incremento del 10,2\% respecto del año anterior. El BOE publicó 214.283 páginas, y el BOCyL 61.308 páginas, un $16 \%$ más que el año anterior. La Unión Europea adoptó 1995 actos jurídicos durante el año 2019. A todo ello hay que sumarle las reglamentaciones municipales, y las resoluciones de los tribunales de justicia. Baste recordar que el censo normativo de Castilla y León efectuado en el año 2011 arrojaba la cifra de casi 3.600 disposiciones. Esto es relevante, ya que según Campos (2020a) un sistema legal complejo, imbricado de requisitos infinitos y de difícil comprensión, favorece el incumplimiento de las normas, la búsqueda de atajos, y la aparición de grietas por las que se cuelan las interpretaciones que facilitan la corrupción.

\subsection{La aparición de una política pública de integridad}

El transcurso del tiempo, la práctica administrativa y la investigación han aportado elementos suficientes como para observar el tema de la integridad pública desde diversos puntos de vista, y de este modo, alcanzar una adecuada conceptualización y selección de los elementos que la integran. 
GAPP. Nueva Época - N. 28, marzo 2022 - ISSN: 1989-8991 - DOI: https://doi.org/10.24965/gapp.i28.10971 - [Págs. 27-47]

\subsubsection{Concepto de integridad pública}

Villoria define la integridad como una virtud que garantiza que las acciones se basan en un marco de principios internamente consistente. "Una persona que actúa de forma íntegra deriva sus acciones y creencias del mismo grupo de valores esenciales; en ella existe una solidez que se deriva de su honestidad y la consistencia de su carácter» (Villoria, 2012, p. 108). Según este autor, un gobierno íntegro es el que asume e implanta los instrumentos, procesos y órganos necesarios para prevenir la corrupción y fomentar un servicio público coherente con los principios y valores que fundamentan su ética profesional en un régimen democrático (Villoria, 2012, p. 109). La inexistencia de integridad implica una clara diversificación de comportamientos que pueden incluirse en el concepto de corrupción: cohecho, negociaciones incompatibles con la función pública y la malversación de caudales públicos, lavado de dinero, narcotráfico, financiamiento del terrorismo, ... (Ivanega, 2018, p. 578). Pero esta ausencia no deriva únicamente en actividades con relevancia penal, sino también de ilícitos administrativos, e incluso prácticas no punibles pero reprobables por constituir abusos, conductas inadecuadas o sospechosas de serlo (la acumulación de cargos públicos, las puertas giratorias, la ineficacia en la gestión, el derroche de recursos públicos, ...).

Apoyados en estas acotaciones, y siguiendo las Recomendación sobre Integridad Pública de la OCDE (2017), se puede definir la integridad pública como «el posicionamiento consistente y la adhesión a valores éticos comunes, así como al conjunto de principios y normas destinadas a proteger, mantener y priorizar el interés público sobre los intereses privados dentro del sector público». Villoria (2012, p. 108) convierte esa actitud y esos principios y normas en un sistema, útil para el propósito de este trabajo, y que resulta expresiva de un conjunto de instrumentos, procesos y órganos interrelacionados entre sí y con entidad propia que son necesarios para prevenir la corrupción y fomentar un servicio público fundamentado en la ética profesional.

\subsubsection{El abordaje de la integridad desde la gobernabilidad y la gobernanza}

A la hora de abordar el problema de la corrupción desde la perspectiva de la gobernabilidad, se puede entender que ésta es capaz de derribar los inconvenientes que se planteaban en relación con su ineficacia, porque en algunos países se han registrado mejoras significativas en períodos cortos de tiempo (Kauffman, 2005, pp. 41-43). A pesar de ello, se sigue cuestionando la eficacia de la gobernabilidad para combatir la corrupción, porque cuenta con una visión estrictamente gubernamental de los problemas, y además con un solo actor que monopoliza los recursos de coerción, dominación y administración (D’Eramo, 2017, pp. 127,128). No en vano, es justamente la existencia de la prioridad en la búsqueda de la gobernabilidad, junto con el sistema electoral mayoritario, las listas cerradas y bloqueadas, el papel preponderante de los partidos políticos y sus líderes en su relación con la Administración, así como la primacía del poder ejecutivo sobre el resto de los poderes e instituciones del Estado, las que generan un marco institucional favorable para la corrupción (Villoria, 2015a, p. 10).

Cobra sentido, por lo tanto, la introducción del concepto de gobernanza para abordar la integridad pública, tanto que la segunda es esencial para comprender la primera (Huberts, 2018, p. 18). Gobernanza entendida como un «estilo de gobierno paradigmático, que sirve para mejorar las relaciones entre los representantes públicos y la sociedad civil, tercer sector y resto de agentes socioeconómicos» (Pérez, 2015 , p. 68). Precisamente, la gobernanza facilita que comience a reivindicarse, para su traslado al sector público, el papel que en el sector privado tiene el compliance (Campos, 2019). Si bien el compliance y la integridad institucional guardan importantes puntos en común (la autorregulación, la prevención, los valores, los canales de denuncia, los órganos de vigilancia), la implementación del primero en la segunda implicaría dar paso a un sistema holístico de integridad institucional. Dicho sistema debería contar con códigos de conducta para la totalidad de empleados públicos, para los ámbitos de la contratación pública, las subvenciones, los procesos selectivos de personal, y para sociedades mercantiles públicas (Jiménez, 2017).

Si bien la gobernanza por sí sola no es garantía para luchar contra la corrupción si no se tiene en cuenta, como advierte Nieto (2007, citado en Ruíz, 2015, p. 86), que debe apoyarse en los principios de participación, transparencia, rendición de cuentas, eficacia y coherencia, que no son otros que los principios establecidos en el «Libro Blanco de la Gobernanza Europea» (2001). 


\subsubsection{El abordaje de la integridad pública desde su evaluación}

Tras la reclamación de varios autores del diseño de políticas integrales contra la corrupción (Villoria, 2015a, p. 11; Ramió, 2015, p. 29), se puede afirmar que los gobiernos han comenzado a moverse en esa dirección, inducidos por la crisis política que contribuyó a que se produjeran cambios en muchos sistemas de partidos de Europa occidental.

Esta tendencia ha tenido su repercusión a nivel regional ya que de trece regiones de España, Italia y Reino Unido analizas por Scantamburlo, Alonso y Gómez, once de ellas (85\%) vieron un aumento en el nivel de atención dedicado por los partidos establecidos a las cuestiones de la regeneración democrática (Scantamburlo et al., 2018, pp. 1,2 y 13). Sin embargo, hay autores como Jiménez (2020) que, menos optimista, ofrece como argumento el último informe del GRECO (Grupo de Estados contra la Corrupción del Consejo de Europa) sobre España (noviembre de 2019) para poner de relieve la falta de preocupación por las cuestiones de integridad institucional, y sostener que en nuestro país se sigue incidiendo en la actuación sancionadora o ex post.

La formulación de una política pública sobre integridad requiere de la interacción entre competencia, transparencia y rendición de cuentas, ligada a la vigilancia constante contra la corrupción (Aulich et al., 2012). Por lo que los riesgos de ineficacia proceden de la ausencia de esos elementos. Incluso, si observamos esos peligros de modo algo más pormenorizado identificamos los siguientes: 1) la debilidad en la rendición de cuentas o accountability interna o su efecto paralizador; 2) la debilidad o parcialidad en la rendición de cuentas externa; 3) la interferencia política excesiva y su utilización partidista; 4) la debilidad de los controles administrativos internos; 5) objetivos inalcanzables, contradictorios, ilegítimos; 6) insuficiencia o inadecuación de recursos para las unidades administrativas; 7) división del trabajo defectuosa, poco clara, propiciatoria de la arbitrariedad; 8) excesiva y no controlada discrecionalidad; 8) expectativas sociales inapropiadas; 9) clientelismo; y 10) captura de las políticas. (Villoria, 2012, p. 110).

\subsubsection{Operacionalización del concepto de «sistema institucional de integridad»}

Esta investigación descansa sobre la idea de integridad institucional como sistema ya que, apoyándonos en la ya citada definición de Villoria (2012, p. 108), resulta expresiva de un conjunto de instrumentos, procesos y órganos interrelacionados entre sí y con entidad propia que son necesarios para prevenir la corrupción y fomentar un servicio público fundamentado en la ética profesional. Reflejaría lo mismo que la OCDE identifica como «Marcos de Integridad organizacional» (Integrity Framework).

Partiendo de esa definición, se pueden identificar diferentes dimensiones, subdimensiones e indicadores que sirvan para abordar la medición y la identificación de los instrumentos, procesos y órganos implementados, y aquellos aún necesarios, para poder evaluar el sistema de integridad institucional en Castilla y León. Para abordar esta tarea se parte, además de la «Recomendación del Consejo de la OCDE sobre Integridad Pública» (2017), de la referencia teórica de cinco autores que identifican diferentes atributos que deben ser incorporados a todo sistema de integridad. González (2006), Campos (2020a), Campos (2020b), Palomar (2016), Villoria (2018) y Jiménez (2020) aportan, con desigual contenido, sistemática y nivel de abstracción, ideas que permiten identificar las dimensiones y subdimensiones de un sistema ideal de integridad institucional que aparece detallado en la Tabla 1 y que se ha utilizado en este trabajo.

TABla 1. Operacionalización del Concepto Sistema de INTEgRidad INSTITUCiOnal

\begin{tabular}{l|l|l}
\hline \multicolumn{2}{c}{ Sistema de Integridad Institucional } \\
\hline \multicolumn{1}{c}{ Dimensiones } & \multicolumn{1}{c}{ Subdimensiones } & \multicolumn{1}{c}{ Indicadores } \\
\hline Reforzamiento institucional & Gobernanza & Portales de transparencia \\
\cline { 3 - 3 } & & Gobierno abierto \\
\cline { 3 - 3 } & \multirow{2}{*}{ Prevención } & Sistemas de participación ciudadana \\
\cline { 3 - 3 } & & Simplificación organizativa \\
\cline { 3 - 3 } & & Simplificación normativa \\
\cline { 3 - 3 } & & $\begin{array}{l}\text { Código de buenas prácticas en } \\
\text { contratación pública }\end{array}$ \\
\cline { 3 - 3 } & & Técnicas de compliance \\
\hline
\end{tabular}


GAPP. Nueva Época - N. 28, marzo 2022 - ISSN: 1989-8991 - DOI: https://doi.org/10.24965/gapp.i28.10971 - [Págs. 27-47]

La construcción de un sistema de integridad institucional en la Administración de Castilla y León (2007-2021)

Luis Heredero Ortiz de la Tabla

\begin{tabular}{|c|c|c|}
\hline \multicolumn{3}{|c|}{ Sistema de Integridad Institucional } \\
\hline Dimensiones & Subdimensiones & Indicadores \\
\hline \multirow[t]{4}{*}{ Cultura de la integridad } & \multirow[t]{2}{*}{ Códigos de conducta } & Códigos de conducta Altos Cargos \\
\hline & & Códigos de conducta empleados públicos \\
\hline & \multirow[t]{2}{*}{ Difusión } & Formación \\
\hline & & Política de personal \\
\hline \multirow[t]{6}{*}{ Rendición de cuentas } & \multirow[t]{3}{*}{ Canales de quejas y denuncias } & Estatuto del denunciante \\
\hline & & Canales y buzones telemáticos de quejas \\
\hline & & $\begin{array}{l}\text { Canales y buzones telemáticos de ética y } \\
\text { buen gobierno }\end{array}$ \\
\hline & Sistemas de Evaluación & Entidad independiente de evaluación \\
\hline & \multirow[t]{2}{*}{ Órganos de garantía } & Órganos externos \\
\hline & & Órganos internos \\
\hline
\end{tabular}

Fuente: Elaboración propia a partir de los trabajos de González (2006), Campos (2020a), Campos (2020b), Palomar (2016), Villoria (2018) y Jiménez (2020).

La operacionalización propuesta en la tabla se puede describir del siguiente modo:

- Dimensión 1: Reforzamiento institucional.

Palomar (2016, p. 4) introduce la idea del reforzamiento institucional para solventar lo que considera una evidente pérdida de relevancia social del conjunto de las instituciones políticas. La percepción del ciudadano al respecto está influenciada por un complejísimo sistema decisional policéntrico, fragmentado e interdependiente, derivado de la existencia de múltiples gobiernos cuyas competencias se solapan entre los distintos niveles territoriales (Castel, 2010, p. 7). Aunque haya habido algún intento loable de clarificar esta situación (Informe CORA ${ }^{3}, 2012$ ), resultó ser una oportunidad perdida.

Esta dimensión denominada «reforzamiento institucional» es delimitada en este trabajo mediante la identificación de dos subdimensiones, que son tomadas del modelo de integridad institucional de Jiménez (2017) y Jiménez (2020): gobernanza y prevención. Gobernanza, que supedita a la Administración a contar con la visión y la participación de los ciudadanos a través de algunos instrumentos que nos han de servir de indicadores, como son los portales de transparencia, el gobierno abierto, y los sistemas de participación ciudadana. Prevención (González, 2006), que nos lleva a incluir indicadores que midan la existencia de una organización administrativa reducida y accesible y con mayor simplificación normativa (Campos, 2020a). Junto a lo anterior, otros indicadores como los códigos de buenas prácticas en contratación (OCDE, 2011) y la puesta en marcha de técnicas de compliance (Jiménez, 2020; Campos, 2020b).

- Dimensión 2: Cultura de la integridad.

La dimensión «Cultura de la Integridad» (Jiménez, 2020) está inspirada en uno de los ejes que la OCDE (2017) propone en su modelo de política de integridad pública. Implica la propagación o divulgación de comportamiento ético por parte de todos los agentes implicados en una organización pública, debe derivar en su compromiso efectivo y sostenido en el tiempo con la integridad, y representa una evidente ventaja respecto de las políticas que implican un control permanente del comportamiento de esos mismos agentes.

En esta dimensión se identifican dos subdimensiones. Por una parte, los códigos de conducta (Villoria, 2018, Jiménez, 2020), que a su vez nos facilitan indicadores útiles para la investigación (códigos de empleados públicos y códigos de altos cargos). Por otra parte, la difusión, que es una subdimensión en la que se identifican dos indicadores: la formación (Villoria, 2018) y la política de personal (Palomar, 2016; Campos, 2020a).

3 Informe de la Comisión para la Reforma de las Administraciones Públicas. 


\section{- Dimensión 3: Rendición de cuentas.}

Si existe una dimensión que es esencial en la política de integridad pública es la rendición de cuentas, porque entendida como control del poder político, constituye un indicador fundamental de la calidad democrática. Se trata de una dimensión crucial en los diversos planteamientos de políticas de integridad pública, y que está presente en el modelo de la OCDE (2017) y en los autores que se han tomado de referencia. Implica la existencia de un mecanismo exhaustivo de evaluación realizado por entidades que mantengan independencia respecto de la organización evaluada. En esta dimensión el papel de los ciudadanos también es importante porque se debe contar con la posibilidad de que sean ellos los que activen los controles que luego podrán ser supervisados por órganos de garantía.

En la dimensión «rendición de cuentas» se han identificado tres subdimensiones. En primer lugar, la subdimensión conformada por los canales de quejas y denuncias (Villoria, 2018; Jiménez, 2020), que nos proporcionan, a su vez, tres indicadores útiles para la investigación: canales y buzones telemáticos de quejas, canales y buzones telemáticos de ética y buen gobierno y el estatuto del denunciante. En segundo lugar, la subdimensión que nos ofrecen los sistemas de evaluación (Palomar, 2016; Villoria, 2018; Jiménez, 2020), en la que identificamos un indicador, que es la existencia de una entidad independiente de evaluación. Por fin, la existencia de órganos de garantía (Jiménez, 2020) se ha configurado como una tercera subdimensión, se la que fácilmente se deducen órganos de garantía internos y externos.

\section{APROXIMACIÓN METODOLÓGICA}

La integridad institucional constituye un fenómeno complejo, multidimensional. En los siguientes subapartados se describen las herramientas de medición y analíticas consideradas en este artículo.

\subsection{Preguntas e hipótesis de investigación}

El objetivo de este trabajo es descriptivo. Desde este punto de vista se trata de dar respuesta a la siguiente pregunta de investigación: ¿los instrumentos de regeneración democrática que ha adoptado la Administración de Castilla y León entre 2007 y 2021 conforman un «sistema de integridad institucional»?

Para dar respuesta a la pregunta de investigación, se va a revisar la política pública de integridad de la Junta de Castilla y León, sus normas, la estructura orgánica de su Administración y su evolución en el periodo 2007-2021, para identificar qué mecanismos, órganos y procesos se han puesto en marcha. De este modo se busca demostrar si constituyen instrumentos aislados resultantes de fugaces propulsiones administrativas o políticas o si, por el contrario, obedecen a la cumplimentación de un sistema de integridad institucional con una perspectiva holística, tal y como se ha señalado para el modelo propuesto por Jiménez (2020).

La hipótesis de la que se parte para responder a la pregunta de esta investigación es que: en Castilla y León, en el periodo 2007-2021, se han implementado numerosas medidas de regeneración democrática que pueden conformar un sistema de integridad institucional, pero se encuentran aún en proceso de formación y desarrollo, y falta la implantación de un sistema continúo de evaluación que le proporcione la consideración de «integral».

\subsection{Unidad de análisis y referente temporal}

La unidad de análisis es la Administración de Castilla y León, que desarrolla las funciones ejecutivas de carácter administrativo, y realiza los cometidos en los que se concreta el ejercicio de la acción de gobierno. En ella se incluyen la Administración General y la Administración Institucional y empresas públicas (organismos autónomos y entes públicos de derecho privado).

El referente temporal considerado va de 2007 a 2021 porque este período permite analizar las actuaciones llevadas a cabo antes y después de la irrupción de las nuevas fuerzas políticas para las que el tema de la lucha contra la corrupción representaba su principal bandera electoral, y porque abarca cuatro legislaturas, dos con un gobierno de mayoría absoluta del Partido Popular, otra en la que el mismo partido gobernó con apoyos puntuales, y la legislatura que finalizó anticipadamente el pasado 20 de diciembre de 2021, en la que existía un gobierno de colación formado por Partido Popular y Ciudadanos. 


\section{LA IMPLEMENTACIÓN DE MEDIDAS DE INTEGRIDAD PÚBLICA EN LA ADMINISTRACIÓN DE CASTILLA Y LEÓN}

A continuación corresponde analizar las medidas de integridad o de regeneración democrática llevadas a cabo por la Junta de Castilla y León, a la luz de las dimensiones, subdimensiones e indicadores que han sido identificadas dentro del «sistema de integridad institucional», para verificar su existencia o, en su caso, su ausencia o sus carencias.

\subsection{Primera dimensión: reforzamiento institucional}

\subsubsection{Subdimensión Gobernanza}

- Portales de transparencia.

La Ley de transparencia, acceso a la información pública y buen gobierno de 2013 concedió dos años a las Comunidades Autónomas y a las Entidades Locales para adaptarse a las obligaciones contenidas en la misma.

En cumplimiento de ese mandato, en el año 2015 se aprobó la Ley de Transparencia y Participación Ciudadana de Castilla y León. Con ella, el gobierno de la Comunidad se obliga a informar sobre el gasto público de las campañas de publicidad institucional, el volumen de endeudamiento de la Comunidad, la estructura de la cartera de la deuda y calendario de vencimiento, la finalidad a la que están destinados los bienes inmuebles propiedad de la Comunidad, o el número de vehículos oficiales de la Comunidad y su uso ${ }^{4}$.

El 21 de octubre de 2021 el Consejo de Gobierno de la Junta de Castilla y León aprobó el Proyecto de Ley de Transparencia, acceso a la información pública y su reutilización de la Comunidad de Castilla y León. Con él se pretende fortalecer el derecho de todos a conocer cómo se toman las decisiones que les afectan, cómo se manejan los fondos públicos o bajo qué criterios actúan nuestras instituciones, e incorporar un régimen sancionador propio.

El catálogo que especifica las obligaciones de publicidad activa de la Junta de Castilla y León fue aprobado en mayo de $2021^{5}$. Y todo ello se concreta en la creación de accesos en el portal de transparencia de la web de la Junta de Castilla y León que conducen a información relevante a los efectos de la configuración del sistema de integridad institucional, que además se ofrece en formatos reutilizables.

Por lo que se refiere a la evaluación de los resultados, los estudios de Transparencia Internacional ofrecen puntuación (sobre 100) de la Administración de Castilla y León que se ofrece en la tabla 2.

TABLA 2. EVOLUCIÓn DE LA PUNTUACIÓN CONCEDIDA POR TRANSPARENCIA INTERNACIONAL A LA JUNTA de CAstilla y LeÓN

\begin{tabular}{ccccc}
\hline \multicolumn{1}{c}{ Año } & $\mathbf{2 0 1 0}$ & $\mathbf{2 0 1 2}$ & $\mathbf{2 0 1 4}$ & $\mathbf{2 0 1 6}$ \\
\hline Puntuación CyL & 90,0 & 90,0 & 100 & 94,4 \\
\hline Media global & 79,9 & 79,9 & 88,6 & 94,0 \\
\hline
\end{tabular}

Fuente: Elaboración propia a partir de los datos de Transparencia Internacional.

En abril de 2021, DYNTRA ha concedido a la Administración de Castilla y León una puntuación de 79,4, que la sitúa en la posición décima, bajando 1,53 puntos desde 2018. El aspecto en el que su modelo es más fuerte es en el bloque de participación y colaboración ciudadana $(92,3)$, y el aspecto más débil es el de información institucional $(66,7)$.

Dado la presencia tan extensa e intensa en la vida de las personas y el ingente volumen de información y su contenido técnico, el reto actual lo constituye su accesibilidad, es decir, que cualquier buscador localice la información requerida.

\footnotetext{
4 De manera paralela y complementaria a todo este sistema que se ha descrito, el 3 de octubre de 2016 se puso en funcionamiento el Portal de Transparencia de la Sanidad de Castilla y León.

5 ORDEN TRA/599/2021, de 12 de mayo, por la que se aprueba el Catálogo de Información Pública de la Administración de la Comunidad de Castilla y León (BOCyL 20 de mayo de 2021).
} 
La transparencia lleva al acceso a la información, y es esencial para promover y facilitar la participación. Todo ello facilita, a su vez, la exigencia de responsabilidades a los gestores públicos (Moreno, 2015, p. 42). Por lo tanto, estamos ante otro de los elementos esenciales para la prevención de la corrupción.

La Junta de Castilla y León, obligada por la Ley de Derechos de los Ciudadanos en sus relaciones con la Administración de la Comunidad de Castilla y León y de Gestión Pública (2010) ha llevado a cabo durante los últimos años la apertura de canales de participación que se analizan a continuación, y que supone el cumplimiento de la subdimensión que hemos identificado como «gobernanza»:

\section{- Gobierno Abierto.}

Se trata de un indicador relevante en el ámbito de la participación y que la Junta de Castilla y León puso en marcha en el año 2012. En 2015 esta práctica política y administrativa se incorporó a la Ley de Transparencia y Participación Ciudadana. Se trata de que la Administración someta a la participación ciudadana los anteproyectos de ley, los proyectos de decreto, las estrategias, los planes y los programas, y otros procesos de toma de decisiones que afecten al interés general de la Comunidad, mediante su inserción en el Portal de Gobierno Abierto durante diez días naturales.

En el gráfico 1 se aprecia la evolución de los últimos años en esta materia:

Gráfico 1. Estadísticas anuales del Portal de Gobierno Abierto desde 2013

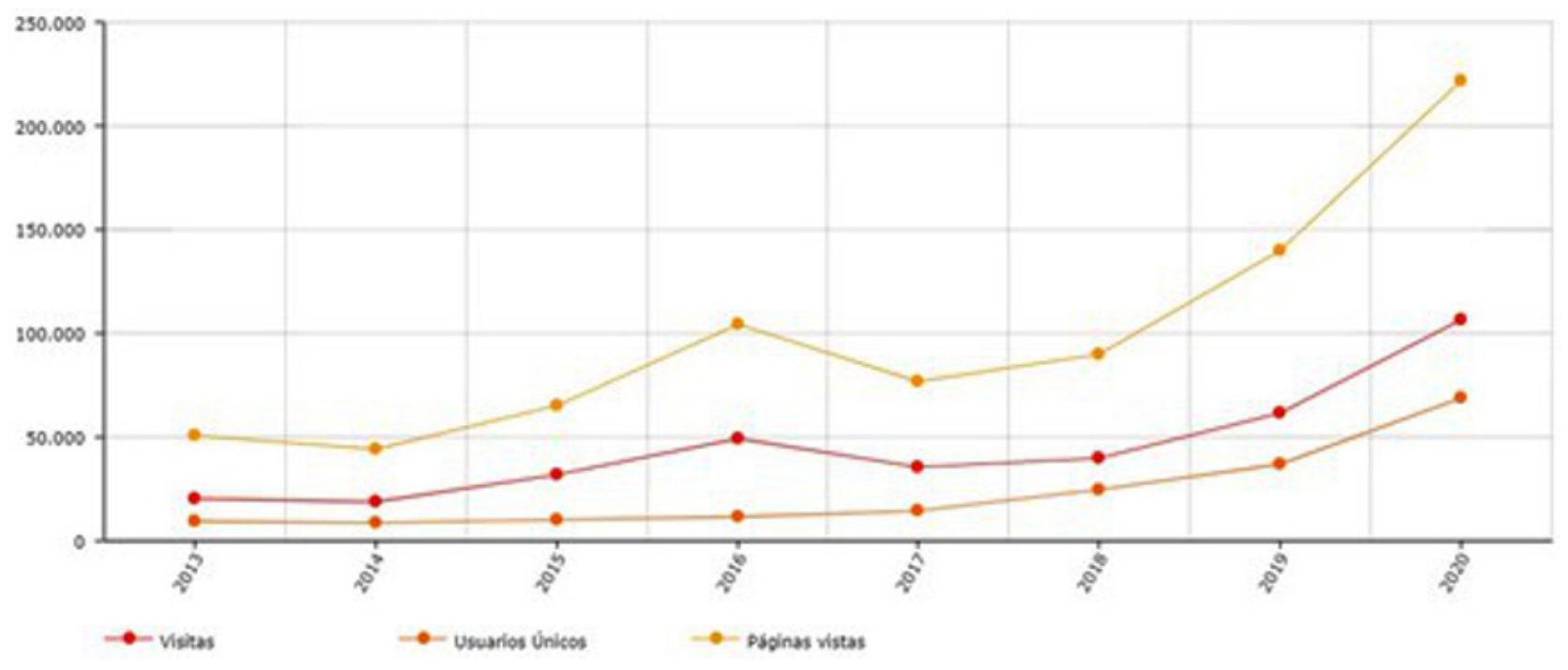

Fuente: wwww.jcyl.es.

Sin embargo, no se ofrecen datos en relación con el tipo de participación que se produce en el proceso de la elaboración de las normas. Solo acudiendo uno a uno a los foros de participación creados se aprecia una intensa producción normativa y una baja participación de los ciudadanos. Así, durante el año 2020 se abrieron 143 foros. En el $61,5 \%$ de ellos no se produjo ni una sola alegación ciudadana, en el $13,2 \%$ hubo una, en el $30 \%$ se hicieron entre 1 y 10 alegaciones, y solo en 5 proyectos hubo más de 30 alegaciones.

- Sistemas de participación ciudadana.

Diálogo social.

Es una práctica política que nació en el año 2001, que se contempló en el Estatuto de Autonomía en 2007, y que cristalizó en institución en el 2008 mediante la creación del Consejo del Diálogo Social. En él participan la Administración autonómica y las organizaciones sindicales y empresariales más representativas de la Comunidad. Desde que se pusiera en marcha, se han suscrito más de cien acuerdos en diversas materias: empleo, protección a las familias y a las personas vulnerables, violencia de género, dependencia, educación, vivienda, infraestructuras, sector forestal, cambio climático. 
Diálogo político.

Respecto a este indicador que hemos incorporado a la idea de "gobernanza», a pesar de que es más difícil de medir, puede admitirse su presencia en la actividad política y administrativa de Castilla y León. Una tercera parte de las leyes de la octava legislatura (2011-2015) se aprobaron con el voto favorable de todos los grupos políticos. Y en la novena legislatura (2015-2019), en la que el PP, además del Acuerdo de investidura y gobernabilidad con Ciudadanos, logró pactos sobre la futura reforma del Estatuto de Autonomía, ordenación del territorio y financiación autonómica (2015), financiación autonómica (2016), y reindustrialización de Castilla y León (2019).

Posteriormente, y tras la derrota electoral del Partido Popular en las elecciones de 2019, fue necesario el acuerdo de gobernabilidad firmado con Ciudadanos para la legislatura 2019-2023. Este acuerdo presenta como novedad algunas cuestiones de gran interés: la creación de una Oficina de Lucha contra el Fraude (cuyo proyecto de ley ha sido aprobado el 15 de julio de 2021), la creación de una Agencia de Evaluación de Políticas Públicas, el refuerzo a la protección de los informantes por delitos de corrupción, la supresión de los aforamientos, la reducción de los puestos de libre designación, o la simplificación burocracia administrativa.

\section{Diálogo civil.}

Existen distintas iniciativas en la Administración analizada que hacen pensar que también se cumple con este parámetro.

a) Consejos de dirección abiertos.

La Ley del Gobierno y de la Administración (2001) regula la existencia de un consejo de dirección en cada consejería, y desde la modificación operada por la Ley del Estatuto del Alto Cargo de 2016, que todas las Consejerías celebren reuniones de ese órgano fuera de su sede ordinaria, reservando un tiempo para recoger sugerencias y propuestas de los ciudadanos y de las organizaciones sociales, que deberá desarrollarse de manera abierta a los medios de comunicación social. Se trata de un canal utilizado durante la legislatura de su creación, pero que en la actualidad ha caído en desuso, estando por determinar si esta circunstancia se ha producido debido a las restricciones derivadas de la pandemia, si bien se podrían haber llevado a cabo de modo telemático. reses.

b) Órganos colegiados de asesoramiento y participación de entidades representativas de sus inte-

En el seno de estos órganos que posibilitan la participación directa de las organizaciones representativas de intereses sociales, se diseñan las políticas y estrategias, se evalúan informes y propuestas, se aporta e intercambia información, se evalúan resultados y los diferentes agentes implicados. El cómputo total de órganos de estas características de carácter regional y provincial suma 112, entre los que se pueden citar, a modo de ejemplo, el Consejo del Deporte de Castilla y León, el Consejo de Transportes de Castilla y León, o el Consejo Regional del Medio Ambiente.

c) Borrador del anteproyecto de Ley de participación ciudadana de Castilla y León (Iniciado el 15 de marzo de 2021).

Con este Anteproyecto se pretende impulsar la participación de los ciudadanos y de los grupos en que se organizan mediante la incorporación de procesos de participación directa en el seguimiento y evaluación de políticas públicas o en la elaboración de normas, y mediante instrumentos como las consultas populares no referendarias, o los presupuestos participativos. Es importante destacar que en este proyecto normativo se ha incorporado la regulación de los lobbies o grupos de interés.

\subsubsection{Subdimensión prevención}

- Simplificación organizativa.

Otro pilar sobre el que se asienta el marco de prevención de la corrupción y fomento de la regeneración democrática en Castilla y León es el de mantener una Administración acorde a los tiempos que se han vivido durante los años más duros de la crisis. Como se puede apreciar en el gráfico 2, atendiendo a un criterio comparativo Castilla y León no tiene un sector público sobredimensionado. 
Gráfico 2. Número de entes públicos por Comunidad Autónoma. ENero 2020

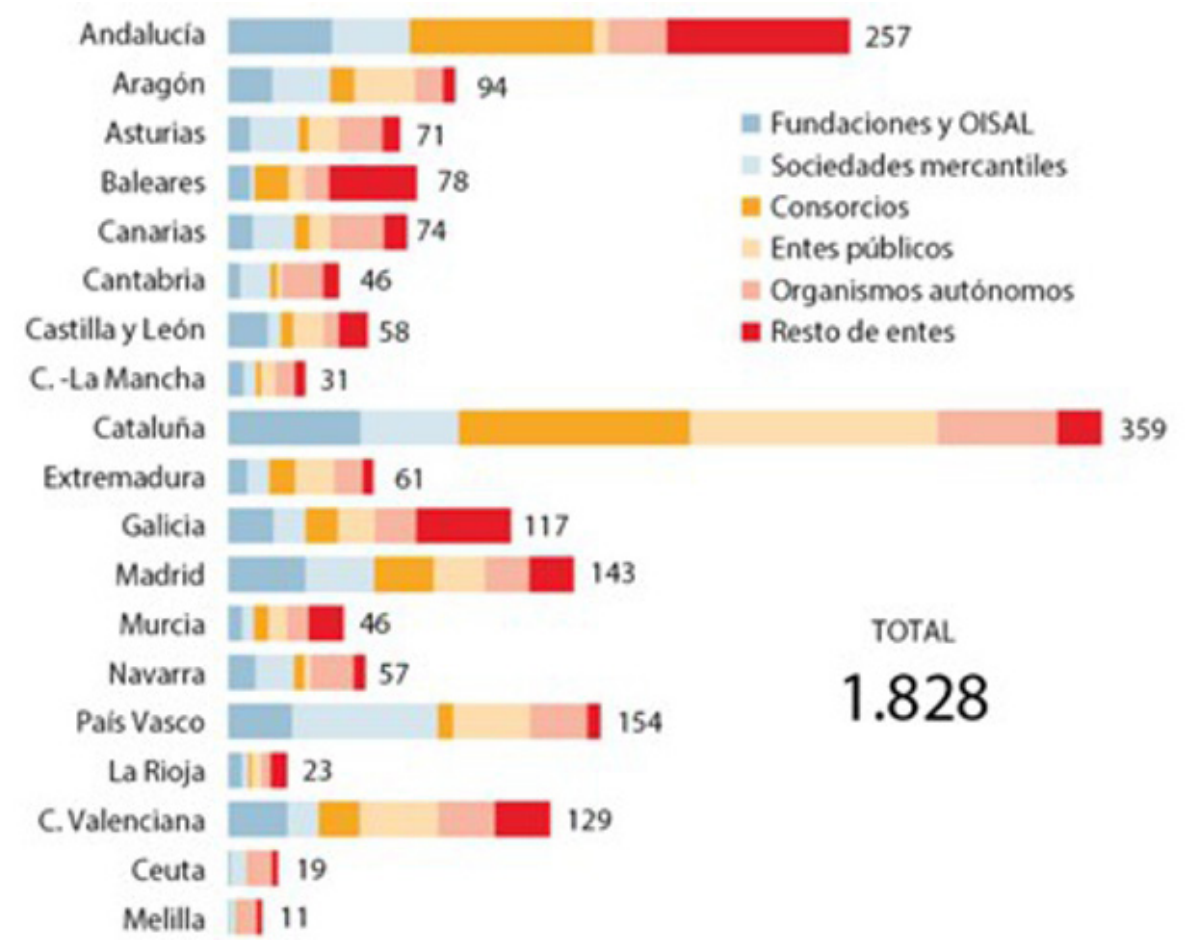

Fuente: ABC.

Conviene recordar que en 2011 se redujo el número de altos cargos, y el número máximo de Consejerías a diez. Respecto de las instituciones propias de la Comunidad se redujo su tamaño con dos medidas: supresión de consejeros en un $40 \%$, y creación de una Secretaría General única. A estas instituciones se les encomendaron nuevas tareas, por ejemplo, las del Tribunal Administrativo de Recursos Contractuales de Castilla y León (TARCCYL), fueron adjudicadas al Consejo Consultivo, y las funciones del Comisionado de Transparencia, al Procurador del Común.

El Plan de Ajuste de la Junta de 2012 fue la respuesta a la obligación impuesta por el Estado para que las Comunidades cumplieran el objetivo de estabilidad fijado para el año $2012(-1,5 \%$ del PIB) y siguientes, implicó la reducción del $29 \%$ (11) de las empresas y fundaciones públicas, partiendo de las 38 sobre las que tiene capacidad de decisión.

En 2014 se redujeron a la mitad de los 110 órganos administrativos inicialmente considerados, a través de la modificación de más de 44 leyes de la Comunidad.

Sin embargo, en la legislatura actual el número de altos cargos se ha incrementado de 69 a 85 altos cargos $^{6}$. También ha sido polémico en sede parlamentaria el aumento de 31 a 44 plazas las plazas de personal eventual o de «asesores» (comparecencia del consejero de la Presidencia el 27 de noviembre de 2019). Se pasa de destinar para este concepto 746.456 euros del presupuesto de 2018 , a 1.596 .965 en el presupuesto de 2021.

\section{- Simplificación normativa.}

En 2019 se aprobó un plan de medidas de mejora de la regulación para el período 2019 a 2023 que ha logrado, por el momento, poner en marcha la «huella normativa» en el Portal de Transparencia. Se ha abordado la simplificación y mejora de la regulación con medidas de limitado alcance práctico inmediato, como la creación una red interna encaminada a compartir información y buenas prácticas, así como un espacio compartido electrónico entre los servicios encargados de tramitar las futuras normas de cada una de las Consejerías.

6 Diario de Sesiones Cortes de Castilla y León, Comisión de la Presidencia, 2 de septiembre de 2019 , pág. 90. 
El plan 2019-2023 incluye el compromiso de la refundición de normas cuando las modificaciones afecten conjunta o separadamente a un tercio de la norma de origen, en que detrás de cada Ley exista tan solo un Reglamento que la desarrolle, en la derogación expresa de todas aquellas disposiciones que lo hayan sido tácitamente en el pasado, y en la aprobación anual de un Calendario Normativo público y transparente, que está ya en marcha.

Se aprecia margen para avanzar en el diseño e implementación de la política pública de mejora de la regulación. Es necesario mantener el compromiso político a lo largo del tiempo, la identificación de los responsables de estas políticas (en la Comisión de la UE el vicepresidente primero es el Comisario de Better Regulation), y la publicación de un informe anual en el Portal de Gobierno Abierto. Del mismo modo, pudiera ser oportuno que en el seguimiento de la implantación de estas medidas tuviera participación alguna entidad independiente.

Existen dos tareas pendientes en esta materia: a) abordar la mejora de la calidad y la disminución de la burocratización, y b) acometer de manera efectiva una reducción y simplificación normativa.

Respecto a la primera, la herramienta fundamental que Castilla y León utiliza es, junto a la tecnología, la producción normativa. Las medidas están siendo implementadas mediante una ingente reglamentación, circunstancia que se comprueba al computar la tramitación simultánea de hasta seis anteproyectos o proyectos de ley con contenidos referidos a esta materia al momento de redactar estas líneas: sobre Agencia de Prevención y Lucha contra el Fraude y la Corrupción, sobre función pública, sobre régimen jurídico de los altos cargos de la Administración, sobre transparencia, acceso a la información pública y su reutilización, sobre participación ciudadana, y sobre Agencia de Evaluación de las Políticas Públicas y la Calidad de los servicios de Castilla y León. Estas leyes se sumarán a las ya existentes sobre garantías de los informantes, derechos de los ciudadanos en sus relaciones con la Administración, gobierno y administración, y a normas estatales que también se ocupan de esta materia.

Para que esas normas vean la luz la Administración cumple un proceso cada vez más exigente. Un anteproyecto de ley pasa por un trámite de consulta pública, por la elaboración de una memoria de análisis de impacto normativo, por un trámite de participación ciudadana, por un trámite de audiencia a Diputaciones, Ayuntamientos, a las secretarías generales de las consejerías y a otras instituciones. Además, existe un trámite de información pública, un informe presupuestario, un informe de los servicios jurídicos, y los correspondientes dictámenes del Consejo Económico y Social y del Consejo Consultivo. A mayores, debe cumplirse la obligación de emitir un informe sobre la evaluación del impacto de género. Y se debe incorporar en la memoria del proyecto normativo un análisis de la contribución de la norma a la sostenibilidad y a la lucha/adaptación contra el cambio climático.

Posteriormente, con el texto ya en sede parlamentaria, se le somete de nuevo al trámite de participación ciudadana.

Respecto a la tarea de reducción normativa, la Junta de Castilla y León relaciona hasta 155 proyectos normativos en el calendario normativo de la Junta para el año 2021, lo cual supone una media de un proyecto cada 2,3 días. Y, aunque una parte de la producción normativa proceda del cumplimiento de obligaciones impuestas por el derecho nacional o el comunitario, existe el riesgo de que su profusión choque frontalmente con la recomendable simplicidad, nitidez, y seguridad que para los ciudadanos tiene que ofrecer las normas que regulan sus relaciones con la Administración.

\section{- Código de buenas prácticas en contratación pública.}

Si bien la Federación Española de Municipios y Provincias y alguna Comunidad Autónoma (Cataluña) han aprobado un código de buenas prácticas, y que otras Administraciones cuentan con un plan sobre esta misma materia (Ayuntamiento de Vigo) no se constata en la Administración de Castilla y León la existencia de parámetros de actuación que puedan servir de guía a los intervinientes en los procesos de contratación pública.

\section{- Técnicas de compliance.}

El compliance en la Administración es un sistema admitido por la OCDE, en su Recomendación sobre Integridad Pública de 2017, procede de las reformas del Código Penal de 2010 y de 2015, e implica «adoptar medidas efectivas para prevenir, detectar y responder adecuadamente, con objetividad e imparcialidad, ante conductas inadecuadas de cualquiera de los individuos que integran una organización» (Pellicer, 2017, p. 4).

Resulta interesante el acercamiento a esta tendencia y a sus posibilidades de aplicación en la Administración de Castilla y León, que el 15 de abril de 2021 definió las funciones de asesoramiento jurídico pre- 
GAPP. Nueva Época - N. 28, marzo 2022 - ISSN: 1989-8991 - DOI: https://doi.org/10.24965/gapp.i28.10971 - [Págs. 27-47]

La construcción de un sistema de integridad institucional en la Administración de Castilla y León (2007-2021)

ventivo que se atribuyen a sus Servicios Jurídicos. Se distinguen cuatro tipos de compliance: administrativo, penal, de mediación intrajudicial, y de gestión del conocimiento. Hasta el momento se observa la actividad de este instrumento de integridad institucional de reciente creación en dos informes emitidos en el ámbito del compliance administrativo.

\subsection{Segunda dimensión: cultura de la integridad}

\subsubsection{Subdimensión códigos de conducta}

- Códigos de conducta empleados públicos.

Puede darse por cumplido este parámetro en la medición que se está efectuando. El origen de los códigos de conducta en Castilla y León lo encontramos en los valores de la Ley de Función Pública (2005), aunque habrá que esperar a 2010 para contar con un Código Ético de sus empleados públicos, que en realidad «no contiene normas jurídicas de obligado cumplimiento... El espacio del Código Ético no puede ser otro que hacer de puente entre los comportamientos legales, que constituyen el actuar ordinario de los empleados públicos, y la consecución de la excelencia en el servicio público, objetivo principal al que responde, en definitiva, la publicación de este Código» (preámbulo).

- Códigos de conducta Altos Cargos.

Se trata de un instrumento presente en el modelo analizado y en continua revisión.

En 2011 se aprobó en Castilla y León un «Código de Austeridad» para los Altos Cargos, que se amplió en octubre de 2015, y por fin se actualizó en mayo de 2020, y es el vigente "Código ético y de austeridad». Mientras tanto, en 2016 se aprobaba el «Estatuto de los Altos Cargos».

La Tabla 3 muestra ejemplos de medidas previstas para cada uno de los valores propuestos:

TABla 3. Ejemplos de medida para cada valor del Código Ético

\begin{tabular}{ll}
\hline \multicolumn{1}{c}{$\begin{array}{c}\text { Código ético y de austeridad } \\
\text { de los Altos Cargos (2020) }\end{array}$} & \multicolumn{1}{c}{ Medidas previstas para cada valor } \\
\hline Imparcialidad & $\begin{array}{l}\text { No formarán parte de las mesas de contratación, de órganos de selección } \\
\text { de personal, ni de comisiones de valoración de subvenciones. }\end{array}$ \\
\hline Transparencia & $\begin{array}{l}\text { Publicarán los actos y reuniones públicas previstas para el desarrollo de } \\
\text { sus funciones. }\end{array}$ \\
\hline Ejemplaridad & No apoyarán peticiones de indulto. \\
\hline Austeridad & Regulación uso del coche oficial. \\
\hline Eficiencia y eficacia & Colaborarán activamente en la evaluación de las políticas públicas. \\
\hline
\end{tabular}

Fuente: Elaboración propia a partir de su publicación en el BOCyL.

El 3 de junio de 2021 se publicó en el Portal de Gobierno Abierto el Anteproyecto de Ley por la que se regula el régimen jurídico de los altos cargos de la Administración de la Comunidad de Castilla y León y de sus entidades adscritas. Se trata dar una vuelta de tuerca al Código del Alto Cargo de 2020, e implica mayores exigencias y garantías para el nombramiento y desempeño de la función del alto cargo. El texto propuesto prevé que los miembros del gobierno puedan elegir a los colaboradores entre aquellos empleados públicos que se hayan postulado para ejercer tales responsabilidades, previa acreditación de su especial cualificación y méritos.

En la búsqueda de la profesionalización del alto cargo, se aprecia una cierta imposición de la condición de funcionario para el acceso a los puestos políticos, excluyendo o dificultando a otros profesionales el acceso a los mismos. Luchar contra la corrupción o contra el modelo clientelar no debería significar la despolitización absoluta de los organismos públicos, porque la legitimidad, la energía y la renovación de los servicios y políticas públicas dependen en esencia del ingrediente político. Incluso en los organismos públicos muy técnicos y especializados las decisiones estratégicas deben tener una naturaleza política (Ramió, 2021). Entre 
GAPP. Nueva Época - N. 28, marzo 2022 - ISSN: 1989-8991 - DOI: https://doi.org/10.24965/gapp.i28.10971 - [Págs. 27-47]

La construcción de un sistema de integridad institucional en la Administración de Castilla y León (2007-2021)

Luis Heredero Ortiz de la Tabla

la colonización política de la Administración, y la funcionarización de todos los espacios de la acción administrativa, existe un lugar intermedio donde el político sea compatible con una dirección pública profesional.

\subsubsection{Subdimensión difusión}

- Formación.

La Escuela de Función Pública de Castilla y León realiza su aportación al fomento de la integridad pública en el seno de la organización mediante la realización de cursos para los empleados públicos como: «Principios y conductas éticas en la Función Pública», «La integridad como competencia profesional», «Gobierno Abierto», «Transparencia: publicidad activa y acceso a la información», «Reutilización de la información del sector público. Open Data», «Utilización eficiente de recursos públicos», y «Evaluación de políticas públicas», o «Transparencia y rendición de cuentas efectivas como instrumento estratégico».

\section{- Política de personal.}

Se trata de un indicador de medición compleja, porque los ámbitos que abarca son muy numerosos y de desigual trascendencia. Sin embargo, puede identificarse que aunque se ha iniciado el proceso hacia el reconocimiento de la carrera profesional horizontal, debe abordarse la configuración de una función pública directiva, la necesidad de implantar la evaluación del desempeño y sistemas de promoción horizontal, la captación de talento, y la preparación para la renovación generacional y la revolución tecnológica. Pero, sobre todo, la Administración debe hacer un esfuerzo por mejorar la percepción exterior y, por consiguiente, incrementar la confianza en un colectivo del que depende la implementación de los servicios públicos, y cuya inamovilidad en el puesto de trabajo es un ingrediente fundamental para la consecución de la objetividad en la toma de decisiones, y esta, a su vez, de la integridad institucional.

El 14 de junio de 2021 se publicó en el Portal de Gobierno Abierto un nuevo Anteproyecto de Ley de Función Pública de Castilla y León. Este texto aborda la regulación de la carrera profesional, y delimita de nuevo el ámbito de la provisión de puestos por el sistema de libre designación. Sin embargo, se pierde la oportunidad de establecer la obligatoriedad de la existencia del concurso general, abierto y permanente de funcionarios, requisito importante para el mantenimiento de una organización íntegra.

\subsection{Tercera dimensión: rendición de cuentas}

\subsubsection{Subdimensión Canales de quejas y denuncias}

- Canales y buzones telemáticos de quejas.

En la Administración de Castilla y León existen diferentes vías de contacto entre los ciudadanos y las unidades administrativas y sus responsables. En su mayoría son canales genéricos de interlocución, pensados para la obtención de información sobre trámites administrativos. En este sentido, funcionan el teléfono 012 y los puntos de contacto de todos los portales web. Existe además un canal denominado «el presidente responde» (gráfico 3 ) que permite enviar un e-mail al presidente de la Junta con iniciativas o propuestas; y existe el buzón de sugerencias y quejas (gráfico 4), pensado para la presentación de reclamaciones relacionadas con el funcionamiento de la Administración.

\section{- Estatuto del denunciante.}

Al constatarse que los canales existentes no constituían un acceso adecuado para denunciar casos de corrupción o malas prácticas administrativas, en 2016 se dictó una ley que regula las actuaciones para dar curso a las informaciones que reciba la Administración Autonómica sobre hechos relacionados con delitos contra la Administración y se establecen las garantías de los informantes. Sin embargo, esta Ley no preveía el acceso confidencial al procedimiento, el cual se sustancia en la Inspección General de Servicios, que es un órgano de la propia Administración.

Para solventar esta cuestión se ha aprobado el 15 de julio de 2021 el proyecto de ley por el que se regula la Agencia de Prevención y Lucha contra el Fraude y la Corrupción, y se establece el estatuto de las personas denunciantes. Del contenido del proyecto se deduce que la nueva Agencia asumirá la responsabilidad en esta materia estará adscrita a las Cortes, y que «actuará con plena independencia y autonomía en el ejercicio de sus funciones». 
Gráfico 3. Evolución de la fRecuencia de uso del CANAL «EL PRESidente Responde» (2015-2020)

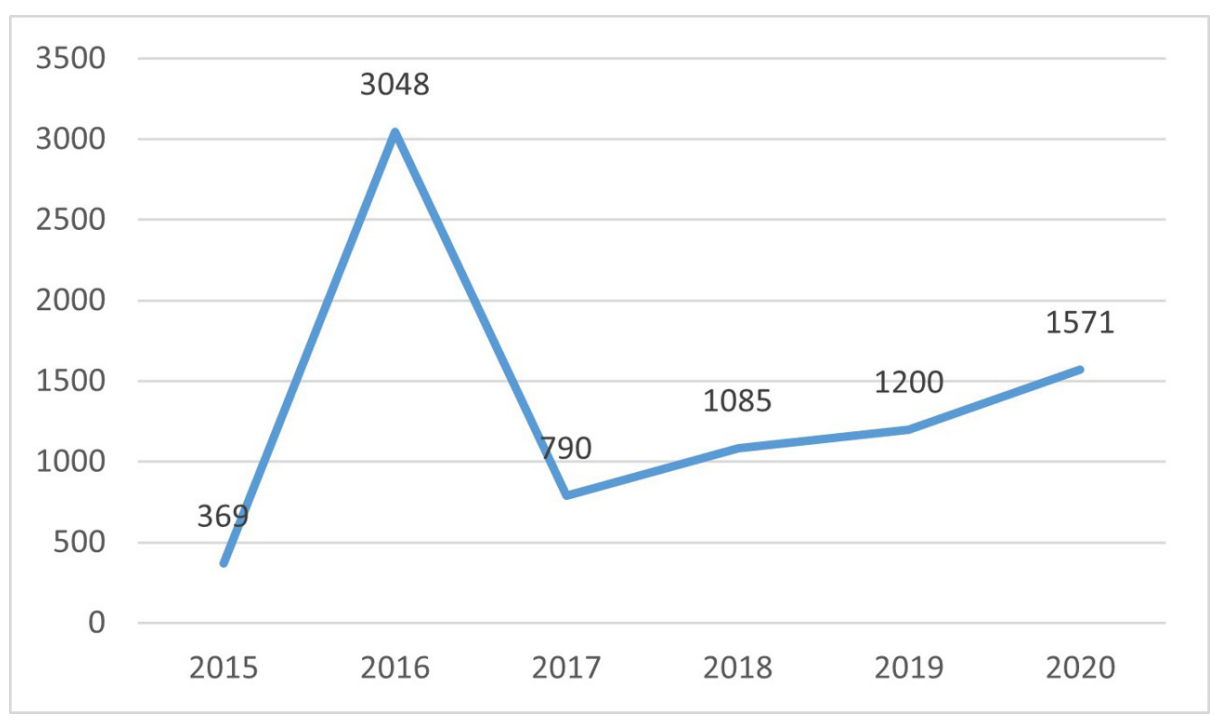

Fuente: Elaboración propia a partir de datos del Portal de Gobierno Abierto.

\section{Gráfico 4. Frecuencia de uso del CANAL de «QUeJAS Y Sugerencias» (2015-2020)}

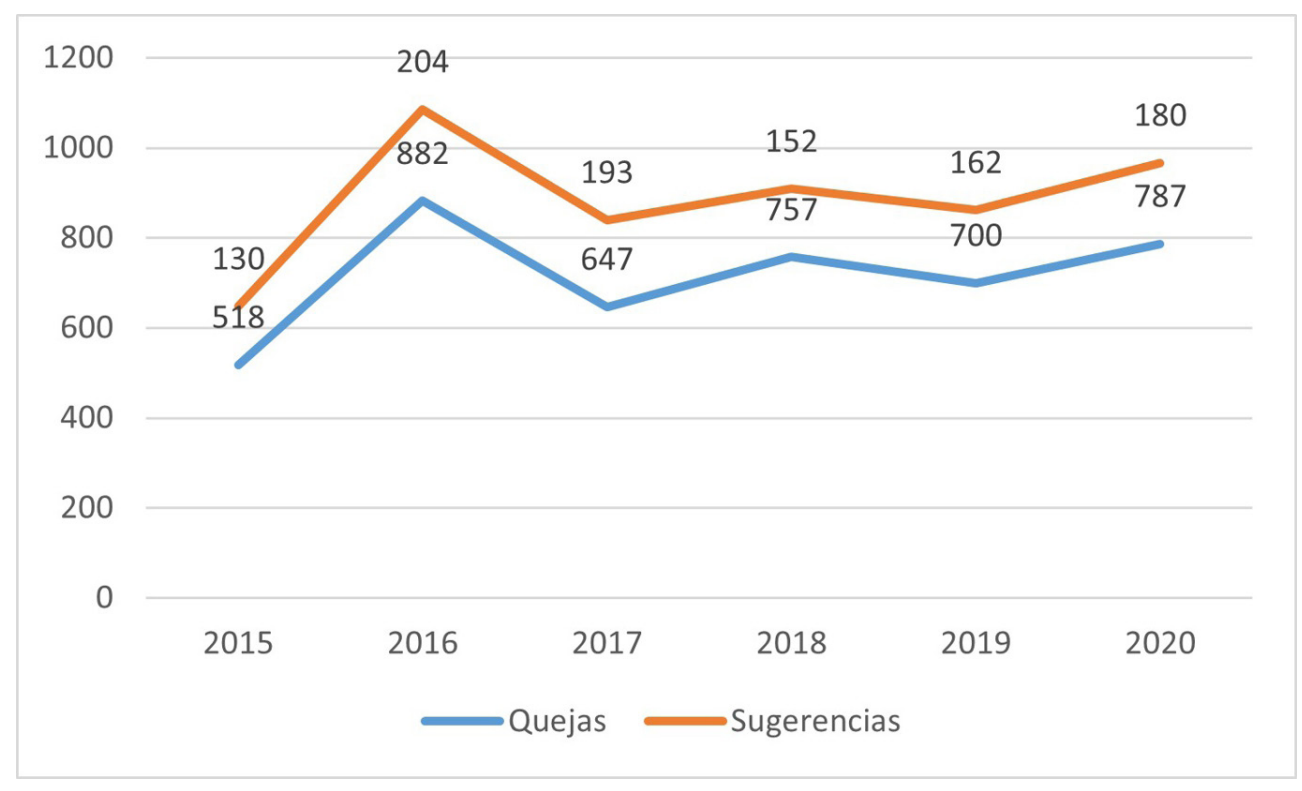

Fuente: Elaboración propia a partir de datos del Portal de Gobierno Abierto.

- Canales y buzones telemáticos de ética y buen gobierno.

El mismo proyecto de Ley que se acaba de citar se crean los «canales de denuncia», inexistentes por el momento. En la regulación propuesta se detalla que deberán permitir la presentación de las denuncias por escrito, por correo, a través de un buzón físico, a través de una plataforma en línea, ya sea en la intranet o en internet, y verbalmente, por línea de atención telefónica, a través de otro sistema de mensajería vocal y, previa solicitud del denunciante, por medio de una reunión presencial o mediante procedimientos telemáticos. 


\subsubsection{Subdimensión Sistemas de Evaluación}

- Entidad independiente de evaluación.

Ferraro (2009, p. 105) considera que las políticas públicas constituyen un proceso continuo e incesante, con diferentes etapas que deben ser consideradas al modo de un ciclo, en permanente movimiento, y que podemos representar de manera circular (gráfico 5).

\section{Gráfico 5. Ciclo de las políticas públicas}

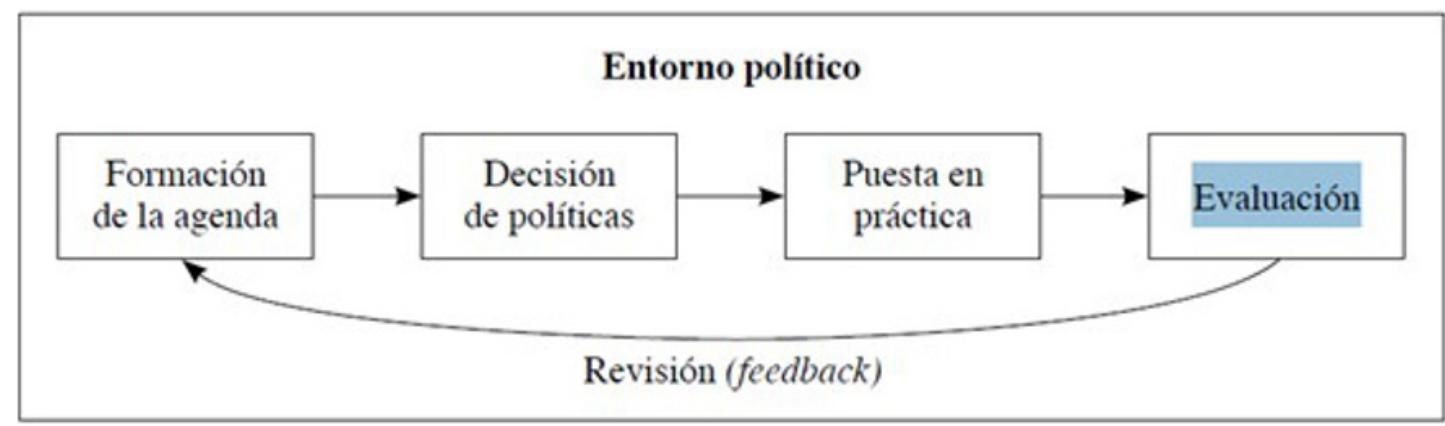

Fuente: Ferraro (2009, p. 107).

Aplicando este proceso, la existencia de un modelo exhaustivo de evaluación o rendición de cuentas públicas aparece como un indicador esencial de la política pública de integridad institucional que contribuye decisivamente a infundir confianza en la Administración.

En Castilla y León, en el año 2010 se le dio rango de ley a la evaluación de las políticas públicas y de la calidad de los servicios de la Administración. Se estableció la necesidad de analizar integral y objetivamente la calidad, eficacia y eficiencia de las políticas públicas, de los planes y programas que se ejecutan para la consecución de los objetivos de esas políticas y de los servicios públicos, y se marcaron parámetros para hacerlo. Sin embargo, esa previsión legal no ha tenido efectos prácticos. En la actualidad es uno de los compromisos pendientes para la presente legislatura, al que se van a dedicar 481.599 euros en el ejercicio 2021, fundamentalmente para que Autoridad Independiente de Responsabilidad Fiscal (AIReF) efectúe un estudio sobre las necesidades de Castilla y León para la implantación de dicho sistema y la creación de la Agencia Autonómica de Evaluación.

Por lo tanto, queda pendiente la creación de esta Agencia como administración independiente, dedicada a la promoción y realización de evaluaciones y análisis de impacto de las políticas y programas públicos, así como el impulso de la gestión de la calidad de los servicios.

\subsubsection{Subdimensión órganos de garantía}

- Órganos externos.

La Administración de Justicia y la Fiscalía. Se trata de mecanismos cuyo ámbito de actuación está referido, en el terreno de la corrupción, a todas las administraciones, y no solo a la autonómica. El Consejo General del Poder Judicial cuenta, desde 2017, con el repositorio de procedimientos por corrupción.

Consejo de Cuentas (2002) es la institución autonómica, dependiente de las Cortes de Castilla y León, encargada de fiscalizar la gestión económica y financiera del sector público de la Comunidad y demás entes públicos de Castilla y León.

Comisionado de Transparencia (2015), cuyas funciones se le atribuyen al Procurador del Común. Su misión es velar por el cumplimiento de las obligaciones de publicidad activa y salvaguardar el ejercicio del derecho de acceso a la información pública.

Comisión de Transparencia (2015), órgano con tres miembros del equipo del Procurador del Común, con funciones de evaluación, consulta y colaboración. Desde su creación y hasta el 15 de junio de 2021 se ha pronunciado 976 veces. Este órgano ha resuelto las reclamaciones en relación con la actividad de la Junta de Castilla y León en ese mismo período tal y como se muestra en la tabla 4: 
GAPP. Nueva Época - N. 28, marzo 2022 - ISSN: 1989-8991 - DOI: https://doi.org/10.24965/gapp.i28.10971 - [Págs. 27-47]

La construcción de un sistema de integridad institucional en la Administración de Castilla y León (2007-2021)

Luis Heredero Ortiz de la Tabla

Tabla 4. Reclamaciones Resueltas por la Comisión de TRANSPAREncia de Castilla y León CONTRA LA JUNTA DE CASTILLA Y LEÓN (2015-2021)

\begin{tabular}{|c|c|c|c|c|c|}
\hline Total & Estimadas & Desestimadas & Inadmitidas & $\begin{array}{l}\text { Desaparición } \\
\text { del objetol } \\
\text { Concesión de } \\
\text { la información }\end{array}$ & Otras \\
\hline 273 & 125 & 18 & 22 & 83 & 25 \\
\hline
\end{tabular}

Fuente: Elaboración propia a partir de los datos de ctcyl.es.

Está prevista la creación de la Agencia de Prevención y Lucha contra el Fraude y la Corrupción. Con este órgano, adscrito a las Cortes, se pretende reforzar la lucha contra el fraude, la corrupción y cualquier otra actividad ilegal que tenga relación con la gestión económica, financiera y contable del sector público de la Comunidad Autónoma y demás entes públicos de Castilla y León.

Asimismo, está pendiente la creación de la Agencia de Evaluación de las Políticas Públicas y la Calidad de los servicios de Castilla y León.

Según las últimas previsiones, expresadas en sede parlamentaria en abril de 2021, la Junta pretende que, a pesar de lo manifestado en el pacto de gobierno, la creación de esta Agencia no conlleve la creación de una entidad nueva, sino que se adscriba al Consejo de Cuentas. Esta es una de las propuestas que la Autoridad Independiente de Responsabilidad Fiscal (AireF) ha realizado en el avance preliminar del informe encargado por la Junta para institucionalizar la evaluación de las políticas públicas en Castilla y León.

- Órganos internos.

La Consejería de Transparencia, Ordenación del Territorio y Acción Exterior (2019). Le corresponde, entre otras competencias, la coordinación, el seguimiento y la evaluación de las políticas públicas, la dirección, definición e impulso de los planes, proyectos e iniciativas de transformación de la Administración Pública, el establecimiento de criterios de racionalización organizativa, o el impulso y puesta en marcha de medidas dirigidas a la mejora de la calidad de la política.

La Inspección General de Servicios (1985), encuadrada en el órgano anterior, es el clásico instrumento administrativo de comprobación del correcto funcionamiento de los órganos y unidades que conforman la Administración. A través de su trabajo se busca fortalecer la ética y la integridad en la actuación pública, y tiene encomendada la evaluación de los programas, estructuras, procesos, procedimientos, actividades y recursos humanos y materiales.

Desde 2016 existe la Comisión de Ética Pública en Castilla y León, compuesta por tres altos cargos y tres profesores universitarios, con funciones consultivas, de seguimiento del cumplimiento del código ético, sancionadoras en el ámbito del alto cargo, las relacionadas con la elaboración y actualización del Código Ético y de Austeridad de los Altos Cargos.

\section{CONCLUSIONES}

La primera particularidad que encontramos respecto a la política de integridad pública en Castilla y León es que se trata de una política de carácter transversal y que sirve de soporte de todas las demás políticas, de tal modo que ninguna iniciativa, estrategia, plan, o proyecto pueden tener éxito sobre la base de la quiebra de la confianza entre los ciudadanos y los responsables de esos proyectos.

En segundo lugar, esta política de integridad pública es reactiva, porque se pone en marcha cuando ya ha se ha abierto la brecha entre los ciudadanos y las instituciones. El impulso regenerador se inició en la octava legislatura autonómica (2011-2015), y el momento álgido llegó en 2015 y en 2019 como consecuencia de los acuerdos de gobernabilidad entre Partido Popular y Ciudadanos.

En tercer lugar, el impacto positivo de las medidas implementadas en la percepción ciudadana, de llegar a producirse, no lo hace sino a largo plazo. Lo primero que se percibe cuando se instaura un nuevo mecanismo de control son los efectos de su ausencia hasta ese momento. A pesar del esfuerzo realizado por la Junta de Castilla y León en la última década mediante la puesta en marcha de numerosos mecanismos de 
GAPP. Nueva Época - N. 28, marzo 2022 - ISSN: 1989-8991 - DOI: https://doi.org/10.24965/gapp.i28.10971 - [Págs. 27-47]

La construcción de un sistema de integridad institucional en la Administración de Castilla y León (2007-2021)

integridad pública, y de los datos positivos que arroja el repositorio de corrupción del Consejo General del Poder Judicial para la Comunidad, no se produce la correlativa percepción ciudadana, reflejada en el Índice sobre Calidad de los Gobiernos subnacionales en los países de la Unión Europea del Instituto de Calidad del Gobierno de la Universidad de Gotemburgo publicado en mayo de 2021 (Charron et al., 2021, p. 35).

En cuarto lugar, la política de integridad pública se implementa para atajar la corrupción, que es una realidad poliédrica que presenta múltiples manifestaciones o vertientes, y contra todas ellas tiene que mostrar eficacia. De este modo, esta política ha de ser diseñada para prevenir y castigar los comportamientos ilegales, pero también para hacer lo propio con actitudes totalmente legales pero reprobables moralmente, y por último, para eliminar toda sombra de sospecha en los supuestos en los que, lejos de producirse un comportamiento corrupto, simplemente se está sembrando un recelo infundado acerca de la existencia del mismo, mediante un ejercicio irresponsable de oposición política o de manipulación mediática.

En quinto lugar, la actividad de las administraciones, incluida la de Castilla y León, abarca cada vez con más intensidad a un mayor número de ámbitos de la vida de los ciudadanos y de su actividad económica. Esta circunstancia conlleva una sobrecarga de normas, requisitos y procedimientos, muchos de ellos de difícil comprensión, que intensifican y a la vez dificultan la relación de los ciudadanos con la Administración. Este es un terreno abonado para la búsqueda de atajos que desenreden esa relación, y para el nacimiento de prácticas deshonestas.

En sexto lugar, la necesidad de acuerdos de legislatura o de coaliciones de gobierno del partido gobernante en Castilla y León ha hecho más visible la política de integridad pública. Como se ha podido comprobar, durante legislaturas anteriores se habían iniciado importantes medidas en materia de transparencia, gobierno abierto y reducción del sector público. Sin embargo, cuando comienzan a tomar fuerza la política de integridad pública como una política con entidad propia es en las dos últimas legislaturas. En primer lugar por la percepción de los votantes, que manifiesta una preocupación creciente por la corrupción. Pero también porque Ciudadanos, partido que nació con la bandera de la regeneración democrática, adquiere influencia primero, y después responsabilidades de gobierno, y como se ha podido comprobar, incorpora a los acuerdos con el Partido Popular importantes medidas regeneradoras, de las cuales se puede visibilizar fácilmente la creación de una Consejería de Transparencia.

Verificación de la hipótesis planteada.

De acuerdo con la hipótesis de este trabajo, puede concluirse que en Castilla y León, en el periodo 20072021, se han implementado numerosas medidas de regeneración democrática que pueden conformar un sistema de integridad institucional, pero se encuentran aún en proceso de formación y desarrollo, y falta un sistema continúo de evaluación que le proporcione la calificación de «integral».

En este momento, la implantación del sistema de evaluación de las políticas públicas y de la calidad de los servicios de la Administración está en fase embrionaria. Si bien es una materia que desde el año 2010 está contenida en una ley, en la actualidad no existe un diseño de los mecanismos y procesos para hacerla efectiva. No obstante, se está trabajando con la Autoridad Independiente de Responsabilidad Fiscal (AIReF) en esta dirección, y queda pendiente la creación y puesta en marcha de la Agencia de Evaluación de las Políticas Públicas y la Calidad de los Servicios de Castilla y León.

Además de lo anterior, puede afirmarse que el «sistema de integridad institucional» de Castilla y León se encuentra en fase de formación y desarrollo en la medida en la que deben intensificarse los programas puestos ya en marcha de simplificación y calidad de los procedimientos, de la normativa de la Administración autonómica, y de la existencia de un sistema de protección del denunciante.

En este sentido, uno de los mecanismos que se ha puesto en marcha más importante en términos de integridad pública ha sido el plan de medidas de mejora de la regulación en el ordenamiento jurídico para el período 2019 a 2023. En la ejecución de éste se ha creado «la huella normativa» y la aprobación anual de un Calendario Normativo público y transparente. Pero la parte más relevante de este plan, pendiente de cumplir, es el compromiso de la refundición de normas cuando las modificaciones afecten conjunta o separadamente a un tercio de la norma de origen, así como que detrás de cada Ley exista tan solo un Reglamento que la desarrolle, y en la derogación expresa de todas aquellas disposiciones que lo hayan sido tácitamente en el pasado.

Por lo que se refiere a la protección del denunciante, Castilla y León cuenta desde 2016 con una ley que regula las actuaciones para dar curso a las informaciones que reciba la Administración Autonómica sobre hechos relacionados con delitos contra la Administración Pública y se establecen las garantías de los informantes. Como consecuencia de la disolución anticipada de las Cortes ha decaído el proyecto de ley en el que, 
GAPP. Nueva Época - N. 28, marzo 2022 - ISSN: 1989-8991 - DOI: https://doi.org/10.24965/gapp.i28.10971 - [Págs. 27-47]

La construcción de un sistema de integridad institucional en la Administración de Castilla y León (2007-2021)

Luis Heredero Ortiz de la Tabla

además de crear la Agencia de Prevención y Lucha contra el Fraude y la Corrupción de la Comunidad de Castilla y León, se establecía el estatuto de las personas denunciantes y se creaban nuevos cauces de denuncias.

Por último, también queda pendiente por confeccionar un plan o un código de buenas prácticas en materia de contratación pública, que garantice la integridad, la racionalización de recursos y el aprovechamiento de las más novedosas tecnologías.

\section{REFERENCIAS BIBLIOGRÁFICAS}

Aulich, C., Wettenhall, R. y Evans, M. (2012). Understanding integrity in public administration: Guest Editors Introduction. Policy Studies, 33(1), 1-5. https://doi.org/10.1080/01442872.2011.635884

Castel Gayán, S. (2010). El estado autonómico y el gobierno multinivel. En Jornada sobre El estado autonómico visto por la primera generación de la democracia (pp. 1-29). Fundación Manuel Giménez Abad de Estudios Parlamentarios y del Estado Autonómico. https://www.fundacionmgimenezabad.es/sites/default/files/Publicar/ documentacion/documentos/2010/20100419_ot_diaz_terren_jm_es_o_0.pdf

Campos, C. (2019, 27 de julio). 10 entradas muy consultadas sobre public compliance. http://concepcioncampos. org/10-entradas-muy-consultadas-sobre-public-compliance-ii/

Campos, C. (2020a, 12 de diciembre). Cuantas más leyes ¿más corrupción? https://concepcioncampos.org/cuantasmas-leyes-mas-corrupcion/

Campos, C. (2020b, 18 de agosto). ¿Qué es el círculo virtuoso de la integridad pública? https://concepcioncampos.org/ que-es-el-circulo-virtuoso-de-la-integridad-publica/

Charron, N., Lapuente, V. y Bauhr, M. (2021). Sub-national Quality of Government in EU Member States: Presenting the 2021 European Quality of Government Index and its relationship with Covid-19 indicators [Working Paper Series 2021:4]. The Quality of Government Institute. Department of Political Science. University of Gothenburg. https://www.gu.se/sites/default/files/2021-05/2021_4_\%20Charron_Lapuente_Bauhr.pdf

D’Eramo, D. E. (2017). Gobernabilidad, gobernanza... en definitiva, el estado. Administración Pública y Sociedad (APyS), 3, 126-135. https://revistas.unc.edu.ar/index.php/APyS/article/view/15314

Diego Bautista, O. (2005). Los códigos éticos en el marco de las Administraciones Públicas contemporáneas: valores para un buen gobierno. Revista de las Cortes Generales, 65, 123-154. https://doi.org/10.33426/rcg/2005/65/464

Fernández Ramos, S. (2018). La transparencia pública: pasado, presente y futuro. Revista Aragonesa de Administración Pública, 51, 213-243. https://bibliotecavirtual.aragon.es/i18n/catalogo_imagenes/grupo. do?path $=3717846$

Ferraro, A. (2009). Reinventando el Estado: por una administración pública democrática y profesional en Iberoamérica. Instituto Nacional de Administración Pública (INAP).

González Pérez, J. (2006). Corrupción, ética y moral en las administraciones públicas. Civitas.

Hallin, D. C. y Mancini, P. (2008). Sistemas mediáticos comparados: tres modelos de relación entre los medios de comunicación y la política. Editorial Hacer.

Heredero, L. (2009). Análisis de la evolución y régimen jurídico de la administración periférica de las comunidades autónomas [Doctoral dissertation]. Universidad de Salamanca. https://gredos.usal.es/handle/10366/76258

Huberts, L. W. J. C. (2018). Integrity: What it is and Why it is Important. Public Integrity, 20(sup1), S18-S32. https://doi. org/10.1080/10999922.2018.1477404

Ivanega, M. M. (2018). Régimen jurídico contra la corrupción. Corrupción, globalización y control. Revista de la Facultad de Derecho de México, 68(271), 577-594. https://doi.org/10.22201/fder.24488933e.2018.271.65333

Jiménez Asensio, R. (2017, 11 de junio). Compliance e integridad institucional. https://rafaeljimenezasensio. com/2017/06/11/compliance-e-integridad-institucional-1/

Jiménez Asensio, R. (2020, 27 de mayo). Gobernanza ética e integridad institucional. https://rafaeljimenezasensio. com/2020/05/27/gobernanza-etica-e-integridad-institucional/

Kaufmann, D. (2005). Diez mitos sobre la gobernabilidad y la corrupción. Finanzas y desarrollo: publicación trimestral del Fondo Monetario Internacional y del Banco Mundial, 42(3), 41-43. https://www.imf.org/external/pubs/ft/fandd/ spa/2005/09/pdf/basics.pdf

Lizárraga, J. A. R. (2011). La transparencia y la participación pública en la Administración de la Comunidad Foral de Navarra. Revista jurídica de Navarra, 51, 123-154. http://www.navarra.es/home_es/Navarra/Derecho+navarro/ Revista+Juridica+de+Navarra/Sumarios/sumario51.htm

Moreno, J. L. M. (2015). Ética y Derecho en el siglo XXI: Acuñación del Ethos-Areté como moneda de curso legal. Aletheia: Cuadernos Críticos del Derecho, 2, 11-50.

Muñoz, J. (2013). El precio electoral de la corrupción: ¿por qué los votantes la castigan tan poco? Pasajes: Revista de pensamiento contemporáneo, 42, 22-31. https://roderic.uv.es/bitstream/handle/10550/45550/22-1. pdf? sequence $=1$ \&isAllowed $=y$

Organización para la Cooperación y el Desarrollo Económicos (OCDE) (2011). La integridad en la contratación pública: Buenas prácticas de la A a la Z (trad. de I. Sánchez Gil). INAP-OCDE. https://doi.org/10.1787/9789264085084-es 
Organización para la Cooperación y el Desarrollo Económicos (OCDE) (2017). Recomendación de la OCDE sobre Integridad Pública. OCDE. https://www.oecd.org/gov/integridad/recomendacion-integridad-publica/

O'Toole, L. J. (1997). The implications for democracy in a networked bureaucratic world. Journal of Public Administration Research and Theory, 7(3), 443-459. https://academic.oup.com/jpart/article/7/3/443/1027068

Palomar Olmeda, A. (2016). ¿Hay vida en la Administración después de la corrupción? Revista internacional de transparencia e integridad, 1, 1-13. http://revistainternacionaltransparencia.org/wp-content/uploads/2016/09/ ALBERTO-PALOMAR.pdf

Pellicer García, J. L. (2017). Herramientas y propuestas para luchar contra la corrupción en el Sector Público: Ética, transparencia y compliance. Revista Internacional de Transparencia e Integridad, 5, 1-9. http:// revistainternacionaltransparencia.org/wp-content/uploads/2017/12/jose_luis_pellicer.pdf

Pérez, A. C. (2015). La participación ciudadana y el modelo de gobernanza como «praxis» de acción de gobierno para la sostenibilidad económica y reforzamiento de la legitimidad democrática en los gobiernos locales. En J. Marco y B. Nicasio (coords.), La regeneración del sistema: reflexiones en torno a la calidad democrática, el buen gobierno y la lucha contra la corrupción (pp. 63-78). AVAPOL Asociación Valenciana de Politólogos.

Ramió, C. (2015). Corrupción y administración pública en España. En J. Marco y B. Nicasio (coords.), La regeneración del sistema: reflexiones en torno a la calidad democrática, el buen gobierno y la lucha contra la corrupción (pp. 2737). AVAPOL Asociación Valenciana de Politólogos.

Ramió, C. (2021, 31 de mayo). El nuevo modelo de organización pública es un modelo híbrido y abierto. El blog de esPublico. https://www.administracionpublica.com/el-nuevo-modelo-de-organizacion-publica-es-un-modelohibrido-y-abierto/

Ruíz, J. A. (2015). El carácter de servicio de la actividad política requiere la participación ciudadana. En En J. Marco y B. Nicasio (coords.), La regeneración del sistema: reflexiones en torno a la calidad democrática, el buen gobierno y la lucha contra la corrupción (pp. 79-92). AVAPOL Asociación Valenciana de Politólogos.

Scantamburlo, M., Alonso, S. y Gómez, B. (2018). Democratic regeneration in European peripheral regions: new politics for the territory? West European Politics, 41(3), 615-639. https://doi.org/10.1080/01402382.2017.1403148

Villoria, M. y Jiménez, F. (2012). La corrupción en España (2004-2010): datos, percepción y efectos. Revista Española de Investigaciones Sociológicas (REIS), 138(1), 109-134. https://doi.org/10.5477/cis/reis.138.109

Villoria, M. (2012). Integridad. Eunomía: Revista en Cultura de la Legalidad, 1, 107-113. https://e-revistas.uc3m.es/ index.php/EUNOM/article/view/2160

Villoria, M. (2015a). La regeneración democrática: Diagnóstico y propuestas. En En J. Marco y B. Nicasio (coords.), La regeneración del sistema: reflexiones en torno a la calidad democrática, el buen gobierno y la lucha contra la corrupción (pp. 9-26). AVAPOL Asociación Valenciana de Politólogos.

Villoria, M. (2015b). La corrupción en España: rasgos y causas esenciales. Cahiers de civilisation espagnole contemporaine. De 1808 au temps présent, 15. https://doi.org/10.4000/ccec.5949

Villoria, M. (2018). Los sistemas de integridad en las organizaciones: una reflexión desde el enfoque institucionalista del buen gobierno. En J. Rodríguez Alba y G. Lariguet (comps.), Gobierno Abierto y ética (1. ${ }^{a}$ ed., pp. 85-120). Universidad Nacional de Córdoba. https://www.researchgate.net/publication/337929308_Los_sistemas_de_ integridad_en_las_organizaciones_una_reflexion_desde_el_enfoque_institucionalista_del_buen_gobierno 